\title{
TU/e EmonONEN

\section{A numerical and experimental study of the NO-emission of ceramic foam surface burners}

Citation for published version (APA):

Bouma, P. H., Eggels, R. L. G. M., Goey, de, L. P. H., Nieuwenhuizen, J. K., \& Drift, van der, A. (1995). A numerical and experimental study of the NO-emission of ceramic foam surface burners. Combustion Science and Technology, 108(1-3), 193-203. https://doi.org/10.1080/00102209508960398

DOI:

10.1080/00102209508960398

Document status and date:

Published: 01/01/1995

\section{Document Version:}

Publisher's PDF, also known as Version of Record (includes final page, issue and volume numbers)

\section{Please check the document version of this publication:}

- A submitted manuscript is the version of the article upon submission and before peer-review. There can be important differences between the submitted version and the official published version of record. People interested in the research are advised to contact the author for the final version of the publication, or visit the $\mathrm{DOI}$ to the publisher's website.

- The final author version and the galley proof are versions of the publication after peer review.

- The final published version features the final layout of the paper including the volume, issue and page numbers.

Link to publication

\section{General rights}

Copyright and moral rights for the publications made accessible in the public portal are retained by the authors and/or other copyright owners and it is a condition of accessing publications that users recognise and abide by the legal requirements associated with these rights.

- Users may download and print one copy of any publication from the public portal for the purpose of private study or research.

- You may not further distribute the material or use it for any profit-making activity or commercial gain

- You may freely distribute the URL identifying the publication in the public portal.

If the publication is distributed under the terms of Article 25fa of the Dutch Copyright Act, indicated by the "Taverne" license above, please follow below link for the End User Agreement:

www.tue.nl/taverne

Take down policy

If you believe that this document breaches copyright please contact us at:

openaccess@tue.nl

providing details and we will investigate your claim. 


\title{
A Numerical and Experimental Study of the No-Emission of Ceramic Foam Surface Burners
}

\author{
P. H. BOUMA, R. L. G. M. EGGELS, L. P. H. DE GOEY, J. K. NIEUWENHUIZEN \\ Eindhoven University of Technology, Dept. of Mechanical Engineering \\ (WOC, WH 3.138), PO BOX 513, 5600 MB Eindhoven, The Netherlands
}

\author{
A. Van Der DRIFT Netherlands Energy Research Foundation, ECN Fossil \\ Fuels, P.O. Box 1, 1755 ZG Petten, The Netherlands
}

(Received February 15, 1995; in revised form June 22, 1995)

\begin{abstract}
The NO-emission of flat premixed methane-air flames on a ceramic foam surface burner has been studied. This burner is developed for domestic heating systems, drying equipment and small industrial furnaces. A skeletal mechanism for lean-methane oxidation is used to compute the temperature and concentration fields of the major combustion species. The NO-emission is computed with a NO postprocessor using the output of the flame calculation as input. The nitrogen chemistry computation is based on the reaction mechanism of Glarborg et al. (1992). Steady-state relations are introduced for most of the intermediates. In this way convection-diffusion-reaction equations for $\mathrm{NO}$ and $\mathrm{HCN}$ have to be solved only. The computation time is reduced significantly by using these post-calculations instead of solving the complete complex reaction scheme in one computational step. The computed flame temperature, surface temperature and NO-emission is compared with experimental results. The NO-emission is measured at several distances above the burner surface for several thermal loads and air ratios. The agreement with the numerical results shows that the proposed model is valid for predicting the flame temperature, surface temperature and NO-emission of radiant surface burners.
\end{abstract}

Key Words: $\mathrm{NO}_{x}$, premixed, laminar flames, heat transfer and radiation, modelling

\section{NOMENCLATURE}

$\begin{array}{lll}A & \text { Specific area } & \left(\mathrm{m}^{2} / \mathrm{m}^{3}\right) \\ c_{p} & \text { Specific heat } & (\mathrm{J} / \mathrm{kg} / \mathrm{K}) \\ D & \text { Diffusion coefficient } & \left(\mathrm{m}^{2} / \mathrm{s}\right) \\ h & \text { Formation enthalpy } & (\mathrm{J} / \mathrm{kg}) \\ L & \text { Thickness of the burner } & (\mathrm{m}) \\ \dot{m} & \text { Total mass flow rate } & \left(\mathrm{kg} / \mathrm{m}^{2} \mathrm{~s}\right) \\ n & \text { Air ratio } & (-) \\ N & \text { Total number of species } & (-) \\ q & \text { Heat flux density } & \left(\mathrm{W} / \mathrm{m}^{2}\right) \\ T & \text { Temperature } & (\mathrm{K}) \\ t & \text { Time } & (\mathrm{s}) \\ u & \text { Velocity } & (\mathrm{m} / \mathrm{s}) \\ U & \text { Diffusion velocity } & (\mathrm{m} / \mathrm{s}) \\ x & \text { Position } & (\mathrm{m}) \\ Y & \text { Mass fraction } & (-)\end{array}$


Greek Symbols

$\begin{array}{lll}\alpha & \text { Coefficient of transmission } & \left(\mathrm{W} / \mathrm{m}^{2} \mathrm{~K}\right) \\ \bar{\varepsilon} & \text { Effective emissivity } & (-) \\ \lambda & \text { Coefficient of conduction } & (\mathrm{W} / \mathrm{mK}) \\ \phi & \text { Porosity } & (-) \\ \varphi & \text { Equivalence ratio } & (-) \\ \rho & \text { Density } & \left(\mathrm{kg} / \mathrm{m}^{3}\right) \\ \dot{\rho} & \text { Chemical source term } & \left(\mathrm{kg} / \mathrm{m}^{3} \mathrm{~s}\right) \\ \sigma & \text { Constant of Boltzmann } & \left(\mathrm{W} / \mathrm{m}^{2} \mathrm{~K}^{4}\right)\end{array}$

Indices

$\begin{array}{ll}b & \text { Burnt } \\ g & \text { Gas } \\ i & \text { Species number } \\ \text { rad } & \text { Radiation } \\ s & \text { Solid burner material } \\ \text { surf } & \text { Surface of the burner plate } \\ \text { surr } & \text { Surroundings }\end{array}$

\section{INTRODUCTION}

The mean advantages of the ceramic foam surface gas burner, developed by the Netherlands Energy Research Foundation (ECN), are the low NO-emission and the large modulation range. The turn-down ratio is approximately $1 / 20$. This burner will be considered in this paper as it offers new possibilities on the market of the clean burner technology. The most promising applications are domestic heating systems, drying equipment and industrial furnaces up to a thermal load of $1 \mathrm{MW}$.

At a relatively low thermal load, the gas mixture velocity is lower than the adiabatic burning velocity. A flat flame will stabilize very close to or even partly in the burner. As a consequence, the flame is cooled by conductive heat losses and the NO-emissions is low. The energy loss of the flame is radiated to the surroundings by the burner surface. This operation mode is referred to as the radiation mode. At a relatively high thermal load, the gas mixture velocity is larger than the adiabatic burning velocity. Bunsen-type flames appear in this so-called blue-flame mode. In this paper, the flame behaviour in the radiation mode is considered only. The system is more or less one-dimensional in this mode, which simplifies the flow and reaction equations, presented in section 2, considerably. This makes the burner an ideal object to test combustion and NO models. The flame temperature, surface temperature and NO-emission in the radiation mode will be computed and compared with experiments. It will be shown that the developed model is valid to predict combustion and emission features of the burner very well. This makes it possible to develop new burner constructions and applications with low emission features, with the model as design tool.

The flow equations together with the boundary conditions are presented in section 2.1. In section 2.2, the NO post-processor is discussed. The experimental setup is 
shown in section 3. The numerical and experimental results are presented and discussed in section 4 , finally.

\section{MODELLING OF COMBUSTION AND NO-EMISSION}

Reaction schemes of methane-air combustion with nitrogen chemistry are rather large. The mechanism of Miller and Bowman (1989), for instance, consists of more than 200 reactions among 52 chemical components. It is obvious that solving the reacting flow equations with such reaction schemes is a time consuming task. For this reason Glarborg and co-workers (1992) reduced the mechanism of Miller and Bowman to 77 reactions among 28 chemical components recently. Furthermore, the nitrogen chemistry has no significant influence on the major species, flow and temperature profiles (Eggels, 1993). Decoupling the dominant combustion differential equations from the nitrogen chemistry differential equations, and solving the nitrogen chemistry equations in a post-processing step after a first flame calculation step, reduces the CPU-time significantly. This method has been implemented here, as it makes fast computations possible. The combustion equations are given in section 2.1 and the NO post-computation is discussed in section 2.2 .

\subsection{Governing Equations}

The ceramic foam burner used for the experiments is a square plate with dimensions $114 \times 114 \times 11 \mathrm{~mm}^{3}$ and has a porosity $\phi \approx 0.9$. The pores of the foam are small $(0.4 \mathrm{~mm})$ and more or less equally distributed, so that the flow is fairly homogeneously distributed over the surface. Therefore, the system may be considered as one-dimensional in the radiation mode. Numerous 1D-combustion-models have been developed. Our code for burner-stabilized flames (Somers, 1994) has been extended with energy transfer between the gas and the ceramic foam and with radiation heat loss at the surface of the foam (Bouma et al., 1994). The computation is separated in two subsequent parts. For the reaction scheme in the first 'flame calculation step' the skeletal mechanism for lean methane oxidation of Smooke (1991) is used. This scheme consists of 25 reactions among 16 species $\left(\mathrm{CH}_{4}, \mathrm{CH}_{3}, \mathrm{CH}_{3} \mathrm{O}, \mathrm{CH}_{2} \mathrm{O}, \mathrm{HCO}, \mathrm{CO}, \mathrm{CO}_{2}\right.$, $\mathrm{O}_{2}, \mathrm{O}, \mathrm{H}_{2}, \mathrm{H}, \mathrm{OH}, \mathrm{HO}_{2}, \mathrm{H}_{2} \mathrm{O}_{2}, \mathrm{H}_{2} \mathrm{O}$ and $\mathrm{N}_{2}$ ). The related convection-diffusionreaction equations are given by:

$$
\phi \rho_{g} \frac{\partial Y_{i}}{\partial t}+\phi \rho_{g} u \frac{\partial Y_{i}}{\partial x}-\frac{\partial}{\partial x}\left(\phi \rho_{g} D_{i m} \frac{\partial Y_{i}}{\partial x}\right)=\phi \dot{\rho}_{i} \quad \text { with } \quad i \in[1, N],
$$

where the symbols are defined in the list of symbols. The differential equations for the temperature of the gas $T_{g}$ and of the ceramic foam $T_{s}$ are

$$
\begin{aligned}
& \phi \rho_{g} c_{p, g} \frac{\partial T_{g}}{\partial t}+\phi \rho_{g} u c_{p, g} \frac{\partial T_{g}}{\partial x}-\frac{\partial}{\partial x}\left(\phi \lambda_{g} \frac{\partial T_{g}}{\partial x}\right) \\
& =\alpha A\left(T_{s}-T_{g}\right)-\phi \sum_{i=1}^{N} h_{i} \dot{\rho}_{i}-\phi \sum_{i=1}^{N} \dot{\rho}_{g} Y_{i} c_{p, i} U_{i} \frac{\partial T_{g}}{\partial x}
\end{aligned}
$$


and

$$
(1-\phi) \rho_{s} c_{p, s} \frac{\partial T_{s}}{\partial t}-\frac{\partial}{\partial x}\left((1-\phi) \lambda_{s} \frac{\partial T_{s}}{\partial x}\right)=-\alpha A\left(T_{s}-T_{g}\right),
$$

where the porosity $\phi=1$ outside the ceramic foam. The heat transfer term $\alpha A\left(T_{s}-T_{g}\right)$ determines the coupling between the two temperature equations and disappears outside the ceramic foam. The gas temperature Equation (2) is coupled with the $\mathrm{N}$ convection-diffusion-reaction Equations (1) through the chemical source terms $\dot{\rho}_{i}$. The foam is assumed to be chemically inert, which is indicated by the relatively small differences between the numerical and experimental flame and surface temperature (Bouma et al., 1994) performed at different ceramic plates.

The computational domain is presented in Figure 1. The mass fractions of the species $\mathrm{N}_{2}, \mathrm{O}_{2}$ and $\mathrm{CH}_{4}$ and the gas temperature at the first grid point of the computational domain are fixed, while for the remaining species zero gradient boundary conditions are used. At the last grid point, zero gradient boundary conditions are used for all the species and the gas temperature. At the boundaries of the ceramic foam $(x=-L$ and $x=0)$ the solid looses energy by radiation. At the outlet $(x=0)$ the boundary condition for $T_{s}$ is given by:

$$
-\left.(1-\phi) \lambda_{s} \frac{\partial T_{s}}{\partial x}\right|_{x \uparrow 0}=q_{\mathrm{rad}}
$$

where the radiation loss at the surface is represented by $q_{\text {rad }}$ :

$$
q_{\mathrm{rad}}=\bar{\varepsilon} \sigma\left(T_{\mathrm{sur} f}^{4}-T_{\mathrm{surr}}^{4}\right) \text {. }
$$

The radiant boundary condition at the inlet of the foam $(x=-L)$ is similar. Heat transport by radiation inside the foam will increase the effective conductivity of the ceramic foam. However, the influence of radiation in the foam on the combustion behaviour appears to be marginal when the flame is stabilized near the outlet of the foam, so the heat transport by radiation may be neglected. The radiation may not be neglected (Sathe et al., 1990) when the flame is stabilized inside the foam, but that is not the case when surface combustion is considered.

A finite difference discretization method (Thiart, 1990) is used to discretize the equations on a locally-refined grid. To resolve the large gradients near the burner outlet
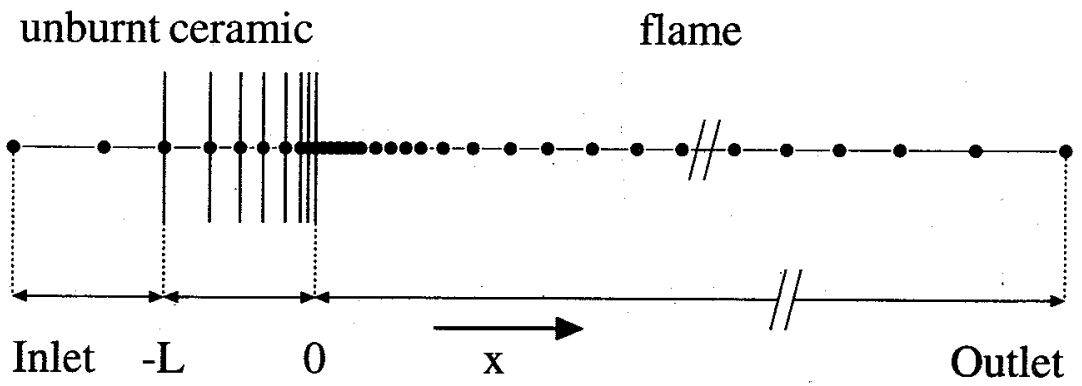

FIGURE 1 Computational domain. The grid points are concentrated around the outlet of the foam near the flame zone. 
and in the flame an adaptive regridding technique (Somers, 1994) is used. The discretized equations are linearized by a fully-implicit Newton method. These linearized equations are solved by standard block-tridiagonal matrix solving techniques, finally.

\subsection{NO Post-Processing}

The mechanism of Glarborg et al. (1992) is used to compute the nitrogen chemistry in a second computational step. The output profiles of the 16 skeletal components, the gas and solid temperature and the grid data of the first flame calculation are fixed and used as input profiles for the NO post-calculation. For the 52 reactions among the 28 chemical components ( 16 species of the skeletal mechanism and the ramaining 12 species: ${ }^{3} \mathrm{CH}_{2},{ }^{1} \mathrm{CH}_{2}, \mathrm{CH}, \mathrm{C}, \mathrm{CH}_{2} \mathrm{OH}, \mathrm{NH}, \mathrm{NCO}, \mathrm{CN}, \mathrm{N}, \mathrm{HCN}, \mathrm{NO}$ and $\left.\mathrm{N}_{2} \mathrm{O}\right) 12$ remaining equations are solved. Steady-state relations are adopted for 10 of the 12 species. Instead of solving the convective-diffusion-reaction equations for those species, coupled algebraic relations are obtained, which are relatively easy to solve. Convection-diffusion-reaction equations for $\mathrm{HCN}$ and $\mathrm{NO}$ have to be solved only.

\section{EXPERIMENTAL SETUP}

A sketch of the experimental setup to measure the NO concentration is shown in Figure 2. The burner will be operated at several thermal loads and air ratios $n$, where the air ratio is related to the equivalence ratio by $\varphi=1 / n$. The premixed methane-air mixture is controlled by mass-flow-controllers. The mixture flows through the burner

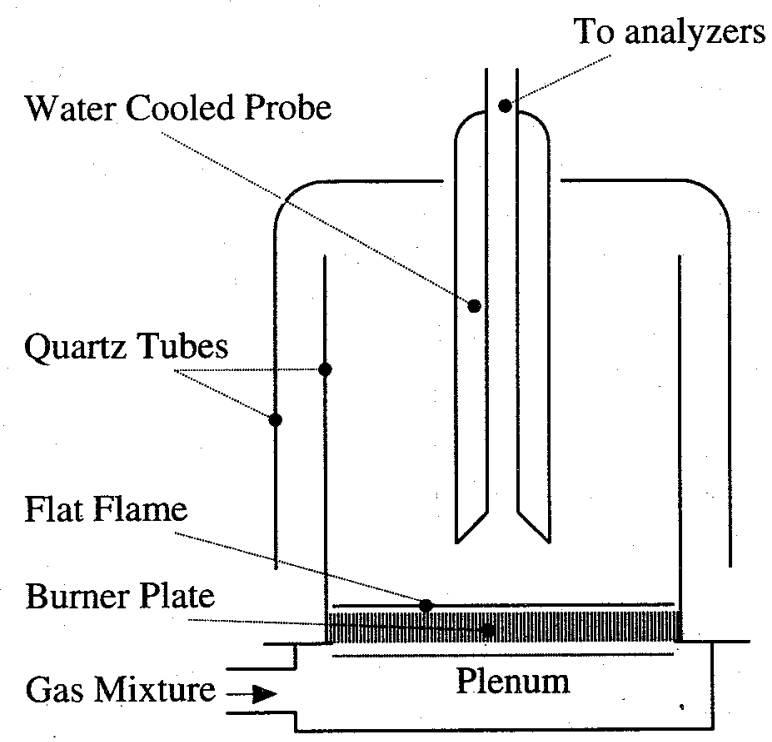

FIGURE 2 Experimental setup. 
plate and is ignited above the burner surface. The combustion chamber consists of two concentric quartz tubes. The flue gases are forced to flow downwards in the annulus between the two quartz tubes. In this way the energy loss of the flue gases due to conduction, diffusion and gas radiation is minimized and the temperature remains almost constant between the burner surface and inlet of the probe.

Thermocouples and a laserpyrometer are used to measure the flame and surface temperature. Thse measurement techniques of the temperatures are described in more detail in Bouma et al. (1994). For the NO-measurements a water cooled suction probe is used at isokinetic conditions to obtain flue gas samples. The distance between the burner surface and the inlet of the probe can be varied from $1 \mathrm{~cm}$ to $10 \mathrm{~cm}$. In this way information is obtained of the NO reaction rate. The gas samples are analyzed after further cooling by a chemoluminiscence analyzer. The accuracy of the analyzer is $1 \%$ of the full scale $(1 \mathrm{ppm})$.

There are two systematical error sources caused by the probe measuring technique. When the distance between the probe and the burner surface is small, the influence of the probe is significant due to radiation of the probe to the burner surface. This effect will result in a local increase of the surface temperature just beneath the inlet of the probe. The flow resistance of the foam is locally increased, which will decrease the local thermal load. As a result, the local flame temperature is lower than the average flame temperature and thus the measured NO-emission also. The local decrease in the thermal load also increases the local residence time. However, this increasing effect on the NO-emission is less dominant than the temperature decrease. The magnitude of this effect depends on the gas temperature, and will therefore be more pronounced at high thermalloads and small air excesses. An analytical estimate indicates that the local thermal load decrease is at most approximately $15 \%$ when the distance between the probe and burner surface is less than $2 \mathrm{~cm}$. This results in an approximate error of maximum $20 \%(15 \mathrm{ppm}$ when the air ratio $n=1.1$, and $5 \mathrm{ppm}$ when $n=1.3)$ in the measured NO-concentration.

The second error source depends on the gas temperature also. Inside the probe the (thermal) NO-forming reactions have to be quenched rapidly. However, at high thermal loads and small air excesses the gas temperature will be high and the quenching rate inside the probe won't be large enough. This will lead to an overestimate of the NO-emission. A numerical estimate of the NO-production in the probe indicates that this systematical error has a magnitude varying between 1 and $10 \mathrm{ppm}$ for gas temperatures between 2000 and $2200 \mathrm{~K}$. This systematic error is therefore significant at small air excesses $(n=1.1)$ and high thermal loads, but plays no role if the air ratio $n=1.3$.

The radiation of the quartz tubes to the burner has an influence on the energy transport at high thermal loads. This radiation energy increases the surface temperature of the foam, which results to a pre-heating of the unburnt gases. When the gas velocity is larger than the adiabatic burning velocity, a so-called super-adiabatic stabilized flame (de Goey et al., 1993) may be obtained. The flame temperature is higher than the adiabatic temperature. This implies that in this specific situation the NO reaction rate will be increased. Due to inhomogeneities of the foam this effect can locally play a role. However, when the gas velocity is smaller than the adiabatic burning velocity this effect does not occur, since pre-heating has no effect on the final gas temperature (de Goey et al., 1993). 


\section{RESULTS AND DISCUSSION}

Figure 3 shows a typical result of the computed gas temperature and the NO-emission of a premixed methane-air flame with air ratio $n=1.1$ at a thermal load of $600 \mathrm{~kW} / \mathrm{m}^{2}$ $(u=21.1 \mathrm{~cm} / \mathrm{s})$. The temperature and the concentration profiles of NO are shown as function of the distance from the burner outlet. The temperature profile is very steep near the burner outlet, where the flame is stabilized. As can be seen, most of the prompt NO is formed in the reaction zone. After a few centimeters, the profile of the prompt NO part is nearly flat. The thermal NO part is formed mainly in the post-flame zone. The production rate of the thermal NO is quite high nearby the flame zone, due to super-equilibrium of the O-radical concentration in that region (Eggels, 1993). After a few centimeters above the burner surface the gradient of the thermal NO becomes constant. The slope of the total NO emission is therefore high nearby the flame zone and becomes constant in the post-flame zone. The experimental NO results are shown by the markers in Figure 3. These results compare well with the numerical results.

The differences between the results of the post-flame calculations and the calculations with the full mechanism in one step without steady-state assumptions have been studied in (Eggels et al., 1993) and are atmost a few percent. It should be noted that subsequent publications of the reaction rate data of the reported NO-reaction schemes show significant differences. This causes an uncertainty in the numerical results, which is much larger than the error in the model assumptions. The computed flame temperature changes from 2072 to $2118 \mathrm{~K}$ (for a stoichiometric mixture) and the NO emission may deviate up to 30\% (Eggels et al., 1993), when reaction rate data of Miller

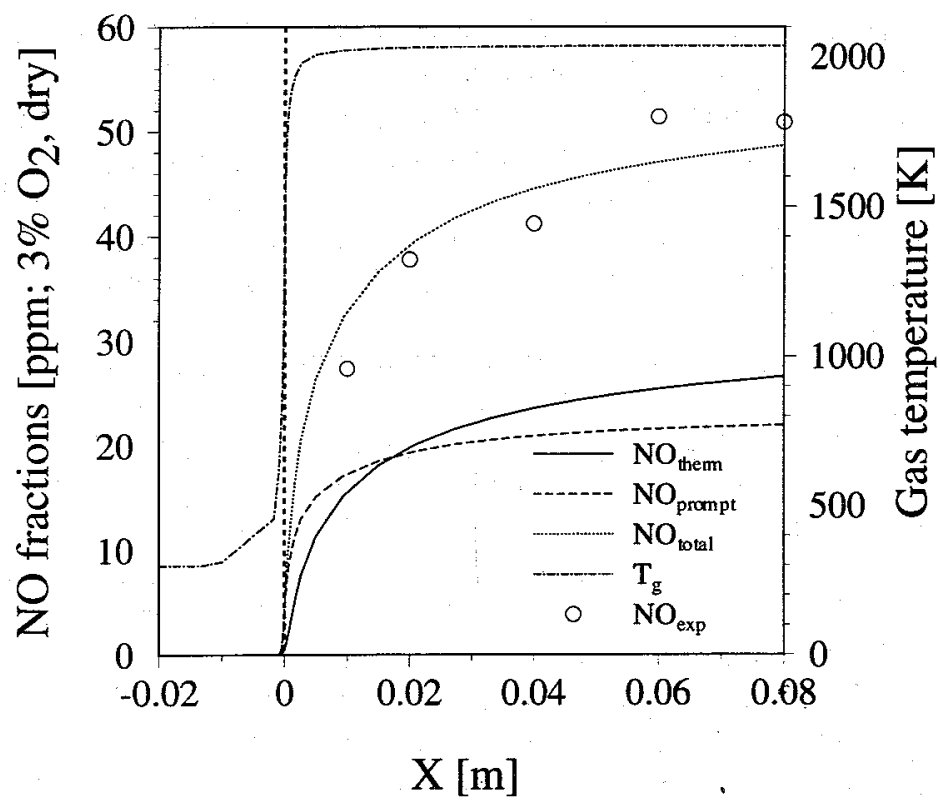

FIGURE 3 Prompt and thermal NO emission of a methane-air flame versus the distance $x$ between burner and probe inlet at a thermal load of $600 \mathrm{~kW} / \mathrm{m}^{2}$ and air ratio $n=1.1$. 


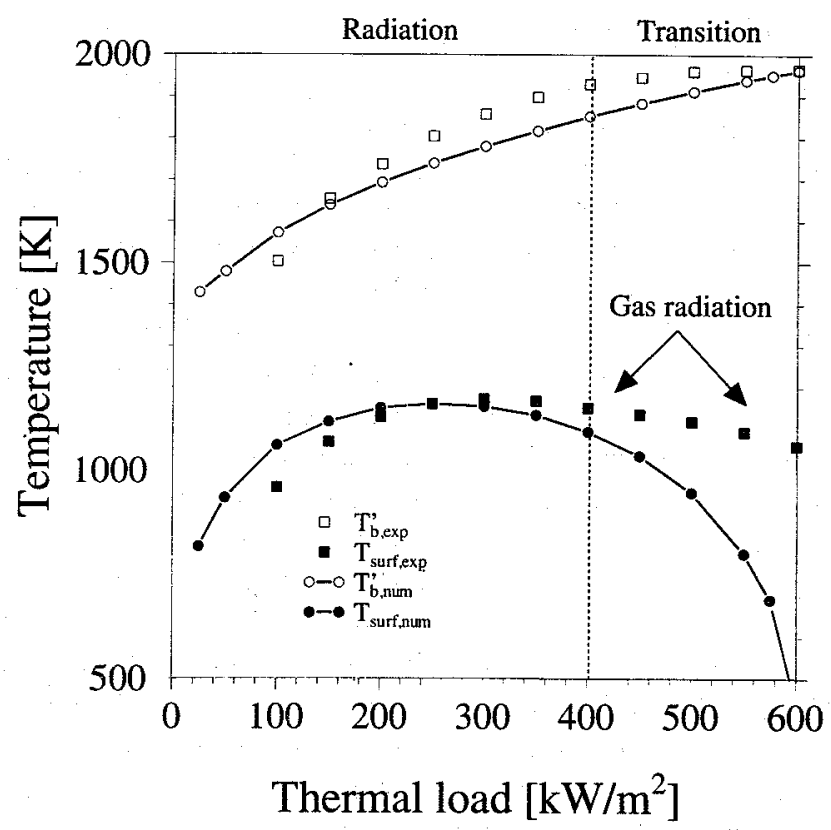

FIGURE 4 Flame $T_{b}^{\prime}$ and surface $T_{\text {sur } f}=T_{s}(x=0)$ temperature versus thermal load at an air ratio $n=1.3$. The markers $O$ and $\bullet$ represent numerical results and the markers $\square$ and experimental results (Bouma et al., 1994).

and Bowman (1989) is used instead of the data given by Glarborg et al. (1992). The recent data of Glarborg et al. (1992) is assumed to be most reliable.

In Figure 4 the measured temperature of the gas and surface are compared with numerical results as a function of the thermal load and for an air ratio of $n=1.3$. Above a thermal load of $400 \mathrm{~kW} / \mathrm{m}^{2}$ (transition region to blue-flame mode) the surface temperature measurements are obscured by gas radiation. The results compare well in the (1D) radiation mode $\left(<400 \mathrm{~kW} / \mathrm{m}^{2} ; n=1.3\right)$. For further discussion of these results see Bouma et al. (1994).

In the Figures 5 and 6 the numerical (lines) and experimental (markers) results for NO are shown as a function of the thermal load for an air ratio of $n=1.1$ and an air ratio of $n=1.3$, which is common use in domestic appliances. The trends found in the experiments are similar to those computed. It is obvious that the NO-emission is larger at an air ratio $n=1.1$ than at $n=1.3$ due to the higher gas temperature.

The variation of both the numerical and experimental NO-concentration with the distance is negligible at an air ratio of $n=1.1$ and at a low thermal load (less than $400 \mathrm{~kW} / \mathrm{m}^{2}$ ). The numerical results shows that the prompt NO mechanism is the most important one in this situation, since the flue gas temperature is too low to produce a significant amount of thermal NO. The variation of the experimental results with the distance are somewhat larger. The measured values at a low distance are probably systematically too small due to the radiation of the probe, as discussed in the previous section. 


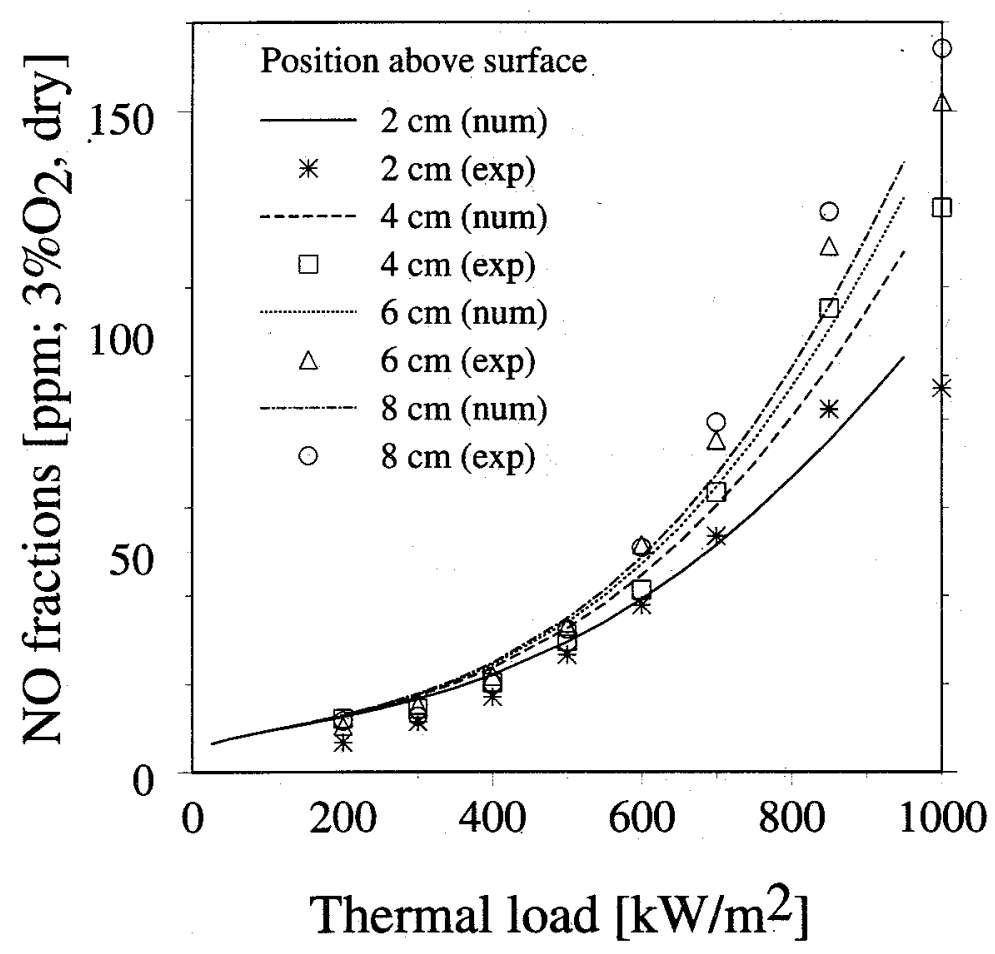

FIGURE 5 NO-emission versus thermal load and position above the burner surface at air ratio $n=1.1$.

At higher thermal loads the influence of the distance increases. The thermal NO part increases significantly. The prompt NO reaction rate also increases. Both effects are mainly caused by the higher flame temperature. At a small distance both mentioned systematical errors play a role. The radiation of the probe will decrease the NOemission, whereas the reactions in the probe will increase the measured values. The experimental results indicate that the quenching error is more pronounced than the radiation error at an air ratio of $n=1.1$ and thermal loads more than $600 \mathrm{~kW} / \mathrm{m}^{2}$.

The absolute values of the NO emission are smaller at the air ratio of $n=1.3$. The difference between the numerical and the experimental results are of the same order as the experimental error (a few ppm). The influence of the probe is less pronounced than at $n=1.1$, due to the lower gas temperature. The quenching inside the probe is fast enough, but the error caused by the radiation of the probe is noticeable at small distances above the burner surface. However, the influence of the radiation is small and of the same order of magnitude as the accuracy of the analyzers.

\section{CONCLUSIONS}

From the presented results we may conclude that the agreement between the numerical and the experimental NO concentrations is satisfactory. The difference is not larger 


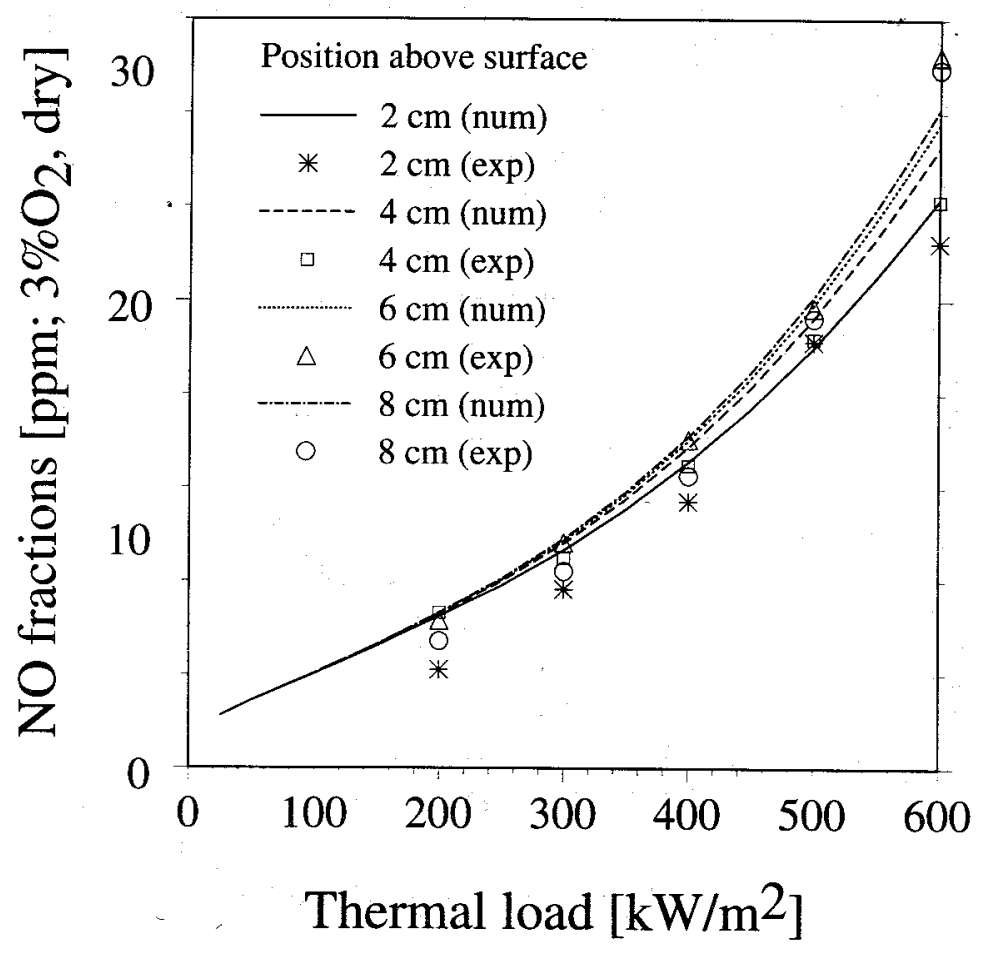

FIGURE 6 NO-emission versus thermal load and position above the burner surface at air ratio $n=1.3$.

than $20 \%$, which is of the same order of magnitude as the accuracy of the measurements indicate. However, we have to emphasize that the influence of the reaction rate data of the reported NO-reaction schemes is significant and may cause an uncertainty of maximum $30 \%$ in the numerical results.

The influence of the probe on the measurements is important at small distances above the burner surface. A new probe head will therefore be constructed, so that the radiation is less centered below the probe. The cooling properties of the probe will be improved also, so that the thermal NO mechanism is quenched rapidly inside the probe, even at an air ratio of $n=1.1$ and high thermal loads.

\section{ACKNOWLEDGEMENTS}

The support of NOVEM and ECN, The Netherlands, is greatefully acknowledged.

\section{REFERENCES}

Bouma, P. H., Somers, L. M. T., de Goey, L. P. H. and Nieuwenhuizen, J. K. (1994). Modelling of Methane-Air Combustion on Ceramic Foam Surface Burners in the Radiation Mode, Eurotherm Seminar \#37, Heat Transfer in Radiating and Combustion Systems, 2, 152-166, Saluggia.

Eggels, R. L. G. M., Somers, L. M. T., de Goey, L. P. H. and Nieuwenhuizen, J. K. (1993). NO-Post Calculations for Flat Laminar $\mathrm{CH}_{4} /$ Air Flames, Second International Conference on Combustion Technologies for a Clean Environment, pp. 12.2 10-14, Lisbon. 
Glarborg, P., Lilleheie, N. I., Magnussen, B. F., Kilpinen, P. and Hupa, M. (1992). A Reduced Mechanism for Nitrogen Chemistry in Methane Combustion, Twenty-Fourth Symposium (International) on Combustion, p. 889.

de Goey, L. P. H., van Maaren, A. and Quax, R. M. (1993). Stabilization of Adiabatic Premixed Laminar Flames on a Flat Flame Burner, Combust. Sci. and Tech., 90, 201.

Miller, J. A. and Bowman, C. T. (1989). Mechanism and Modeling of Nitrogen Chemistry in Combustion, Prog. Energy Combustion Sci., 15, 287.

Sathe, S. B., Peck, R. E. and Tong, T. W. (1993). Flame Stabilization and Multimode Heat Transfer in Inert Porous Media: A Numerical Study, Combust. Sci. and Tech., 70, 93.

Smooke, M. B. (1994). Reduced Kinetics Mechanisms and Asymptotic Approximations for Methane-Air Flames, Lecture Notes in Physics, 384, Springer Verlag Berlin.

Somers, L. M. T. (1994). The Simulation of Flat Flames with Detailed and Reduced Chemical Models, Ph.D. Thesis Eindhoven University.

Thiart, G. D. (1990). Finite Difference Scheme for the Numerical Solution of Fluid Flow and Heat Transfer Problems on Nonstaggered Grids, Numerical Heat Transfer, Part B. 17, 43. 